\title{
Empirical Analysis on the Influencing Factors of Environmental Regulation Performance in Manufacturing Industry: A Case Study of Chongqing, China
}

\author{
Jie Luo ${ }^{1}$, Jie Ren ${ }^{2}$, Pengfei Zhou ${ }^{3,}$, Jia Zhu ${ }^{4 *}$ \\ ${ }^{1}$ School of Geography and Tourism, Chongqing Normal University, Chongqing, 401331, China \\ ${ }^{2}$ Chongqing Yubei District Planning and Natural Resources Bureau, Chongqing, 401120, China \\ ${ }^{3}$ School of Economics and Management, Chongqing Normal University, Chongqing, 401331, China \\ ${ }^{4}$ Chongqing Ecology and Environment Bureau, Chongqing, 401147, China
}

Keywords: Manufacturing industry; Environmental regulation; Factors affecting performance; Empirical analysis

\begin{abstract}
There are many factors influencing the performance of environmental regulation in manufacturing industry. The paper selects five main variables, including economic development level, government environmental protection management level, public environmental awareness, technology level and degree of openness to the outside world. And take Chongqing as a manufacturing big city as a case, Using the calculated data of environmental regulation performance of manufacturing industry, the spatial panel Tobit regression model is constructed to analyze and verify the influencing factors of environmental regulation performance of manufacturing industry, and the corresponding conclusions and countermeasures are put forward according to the five influencing factors.
\end{abstract}

\section{Introduction}

From the perspective of input-output, the paper studies the performance of environmental regulation in Chongqing manufacturing industry, and empirically analyzes the influencing factors, and provides a certain empirical basis for evaluating the performance of manufacturing environmental regulation.

Based on the measured performance of the regulation, a spatial panel Tobit regression model was constructed to analyze the influencing factors of the environmental regulation performance of manufacturing industry in Chongqing. The results show that the level of economic development, government environmental management level, and public environmental awareness have a significant positive effect on the performance of manufacturing environmental regulation. The degree of openness and technology have a significant negative impact on the performance of environmental protection regulation in Chongqing.

According to the conclusions of the empirical research, the paper puts forward corresponding some suggestions on how to improve the environmental regulation performance, including: improving the public participation mechanism, increasing the enforcement of regulations, using diversified regulatory methods, improving the regulatory supervision mechanism, and improving political achievements. Evaluation mechanism.

\section{Data and Methods}

In previous studies, the selection of factors affecting environmental regulation mainly covers the following aspects: (1) Li Zhen and Zhang Hongfeng (2012) choose regional per capita GDP as a measure of economic development level to verify the "Environmental Kuznets Curve" theory; (2) Li Shenglan (2014) choose the ratio of local fiscal expenditure on environmental protection and local fiscal expenditure on general budget to measure the level of government environmental protection management; (3) Ye Xiangsong and Peng Liangyan (2011) choose foreign direct investment (FDI) to measure the level of economic openness and verify the "pollution shelter" 
hypothesis; (4) Wang Peng and Xie Liwen (2014) choose research and development expenditure of large and medium-sized industrial enterprises to measure technological level of enterprises; (5) Tu Zhengge and Liu Leike (2011) choose the proportion of state-owned and state-controlled industrial enterprises in the total output value of large-scale industries to represent the regional ownership structure; (6) Yuan Yijun (2016) choose the proportion of the output value of non-state-owned industrial enterprises in the output value of all industrial enterprises to indicate the market [1]. Besides, there are some scholars choosing the public education level, technical level, fiscal deficit, urbanization level, public awareness of environmental protection as the influencing factors of environmental regulation for analysis.

Based on the research results in relevant literature and the characteristics of environmental regulation in manufacturing industry, this paper chooses the following five variables to verify the influencing factors of environmental regulation performance in manufacturing industry in Chongqing: economic development level, measured by regional per capita GDP, with a unit of RMB1yuan; public awareness of environmental protection, measured by 12369 environmental complaints; the government's environmental protection management level, measured by the ratio of local fiscal expenditure on environmental protection to local fiscal expenditure on general budget; the degree of opening-up, measured by foreign direct investment and other foreign investment, with a unit of US $\$ 10,000$; the technical level, measured by the expenditure on research and development funds of large and medium-sized industrial enterprises, with a unit of RMB10,000 yuan.

This paper constructs a spatial panel Tobit regression model based on the measured environmental regulation performance data of Chongqing manufacturing industry (Table 1 and Figure 1) to analyze the influencing factors of environmental regulation performance of Chongqing manufacturing industry. The original data used in this paper are all from the statistical data published by Chongqing Statistical Yearbook, Chongqing Environmental Status Bulletin, Chongqing Environmental Statistics Bulletin and Chongqing Eco-environment Bureau. The missing individual values in the statistics are smoothed.

Table 1 Average Efficiency and Ranking of Manufacturing Industries in Chongqing from 2008 to 2017

\begin{tabular}{c|c|c}
\hline Year & SBM efficiency & ranking \\
\hline 2008 & 0.9366 & 1 \\
\hline 2009 & 0.7896 & 4 \\
\hline 2010 & 0.7758 & 2 \\
\hline 2011 & 0.8305 & 3 \\
\hline 2012 & 0.8042 & 5 \\
\hline 2013 & 0.7763 & 8 \\
\hline 2014 & 0.7477 & 10 \\
\hline 2015 & 0.7368 & 9 \\
\hline 2016 & 0.6993 & - \\
\hline 2017 & 0.7093 & 6 \\
\hline Average & 0.7806 & 2 \\
\hline
\end{tabular}




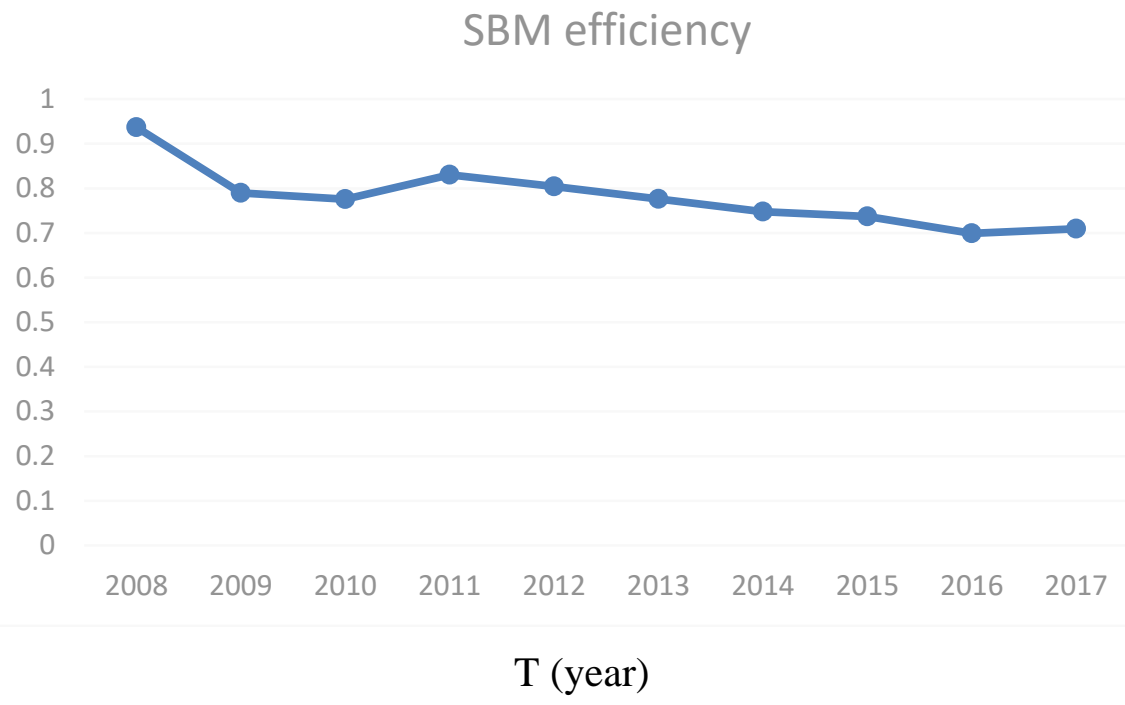

Figure 1 Trend of Overall Efficiency Value of Manufacturing Industry in Chongqing from 2008 to 2017

\section{Model Construction and Empirical Results}

\subsection{Model construction}

The efficiency value calculated by SBM model is regarded as dependent variable. This dependent variable belongs to restricted dependent variable. The efficiency value of SBM is between 0 and 1 . It can be seen from the table that the efficiency of SBM of several decision-making units is 1 , which is on the boundary, resulting in the situation that many samples become a limit value in a specific range. Conventional regression methods can not explain the differences between limit values and non-limit observations, but Tobit regression model can solve this problem. Therefore, this paper chooses Tobit model for regression analysis, and constructs the following Tobit model: $\mathrm{Y}_{\mathrm{it}}=\alpha+\Sigma \beta Z_{i t}+\varepsilon_{i t}$. Among them, $\mathrm{Y}$ is the SBM efficiency value, which represents the environmental regulation performance of Chongqing manufacturing industry. $\alpha$ is the intercept term. $\mathrm{Z}$ indicates the influencing factors of the environmental regulation performance of Chongqing manufacturing industry, which are the level of economic development, public awareness of environmental protection, the level of environmental protection management of the government, the degree of openness to the outside world and the technical level [2]. $\varepsilon$ is a random error term. $\mathrm{i}$ represents the industry, and t represents the year.

\subsection{Empirical results}

Based on the data collected and the established Tobit regression model, the following regression results are obtained after regression analysis with Stata 12.0 software.

\subsubsection{Table 2 gives the basic descriptive statistics of independent variables.}

From 2008 to 2017, the minimum per capita GDP appeared in 2008, which was RMB20490 yuan; the maximum appeared in 2017, which was RMB63442 yuan, with a slightly larger variance and a larger difference in the level of economic development; the level of government environmental protection management differs slightly, and the lowest ratio of local fiscal expenditure on environmental protection to local fiscal expenditure on general budget was 3.19\% in 2014, and the highest was $5.21 \%$ in 2008. Public awareness of environmental protection varies greatly, with the lowest number of complaints in 2009, which is 212,611, the largest number of complaints is 63,458 in 2017. The public awareness of environmental protection has gradually increased [3]. Technical level varies greatly from year to year, and the expenditure on research and development funds of large and medium-sized industrial enterprises in Chongqing was the lowest in 
2008, accounting for 4394.51 million yuan, and the highest in 2017, accounting for 21916.46 Million yuan. The annual difference in the degree of openness to the outside world is also great. The minimum amount of foreign direct investment and other foreign investment is US \$2460.18 million in 2008, and the highest amount is US \$5874.89 million in 2015. Public awareness of environmental protection.

Table 2 Descriptive Statistical Table of Influencing Factors on Environmental Regulation Performance of Manufacturing Industry in Chongqing

\begin{tabular}{|c|c|c|c|c|c|}
\hline & Min. & Max. & Average & SD & Variance \\
\hline Economic Development Level & 20490 & 63442 & 40976 & 4446 & 159767640 \\
\hline $\begin{array}{c}\text { Government Environmental Protection Management } \\
\text { Level }\end{array}$ & 0.0319 & 0.0521 & 0.03818 & 1 & 0 \\
\hline Public Awareness of Environmental Protection & 21261 & 63458 & 42194 & 12613 & 159093810 \\
\hline Technical Level & 439451 & 2191646 & 1213849 & 560867 & 314571242033 \\
\hline Openness to the Outside World & 246018 & 587489 & 410390 & 98056 & 9614926694 \\
\hline
\end{tabular}

\subsubsection{Table 3 gives the correlation analysis of five variables.}

Among them, the GDP per capita is positively correlated with public awareness of environmental protection and technological level. The correlation coefficients are greater than 0.9, and the $\mathrm{p}$ values are close to 0 . It shows that the higher the per capita gross value of regional production, the higher the public awareness of environmental protection, and the more remarkable the technology level. There is a negative correlation between the per capita gross value of regional production and the level of government environmental protection management. The correlation coefficient is -0.674 and the p value is 0.033 . This shows that the higher the per capita gross value of regional production, the lower the level of government environmental protection management, that's to say, the lower the proportion of government financial expenditure on environmental protection [4]. Of course, this does not mean that with the increase of economic income, government expenditure on environmental protection has declined, but the proportion of expenditure on environmental protection has declined. There is also the possibility that expenditure on environmental protection will remain unchanged or increase.

There is a significant negative correlation between the level of government environmental protection management and public environmental awareness and technical level. The correlation coefficients are -0.651 , and the p values are 0.042 and 0.041 respectively. This is because regional per capita GDP has a significant negative correlation with the level of government environmental protection management, while regional per capita GDP has a significant positive correlation with both the public environmental awareness and technological level.

Table 3 Relevant Analysis Table of Influencing Factors on Environmental Regulation Performance of Manufacturing Industry in Chongqing

\begin{tabular}{|c|c|c|c|c|c|c|}
\hline & & $\begin{array}{c}\text { Economic } \\
\text { Development } \\
\text { Level }\end{array}$ & $\begin{array}{c}\text { Government } \\
\text { Environmental } \\
\text { Protection Management } \\
\text { Level } \\
\end{array}$ & $\begin{array}{c}\text { Public Awareness of } \\
\text { Environmental } \\
\text { Protection }\end{array}$ & $\begin{array}{l}\text { Technical } \\
\text { Level }\end{array}$ & $\begin{array}{c}\text { Openness to } \\
\text { the Outside } \\
\text { World }\end{array}$ \\
\hline \multirow{2}{*}{$\begin{array}{l}\text { Economic Development } \\
\text { Level }\end{array}$} & Relevance & 1 & $-0.674^{* *}$ & $0.958^{\text {****}}$ & $0.996^{* * *}$ & 0.462 \\
\hline & sig & - & 0.033 & 0 & 0 & 0.179 \\
\hline \multirow{2}{*}{$\begin{array}{c}\text { Government } \\
\text { Environmental } \\
\text { Protection Management } \\
\text { Level }\end{array}$} & Relevance & $-0.674^{* *}$ & 1 & $-0.651^{* *}$ & $-0.651^{* *}$ & 0.415 \\
\hline & $\operatorname{sig}$ & 0.033 & - & 0.042 & 0.041 & 0.233 \\
\hline \multirow{2}{*}{$\begin{array}{l}\text { Public Awareness of } \\
\text { Environmental } \\
\text { Protection }\end{array}$} & Relevance & $0.958^{* * *}$ & $-0.651^{* *}$ & 1 & $0.935^{* * *}$ & $0.552^{*}$ \\
\hline & $\operatorname{sig}$ & 0 & 0.042 & - & 0 & 0.098 \\
\hline \multirow{2}{*}{ Technical Level } & Relevance & $0.996^{* * *}$ & $-0.651^{* *}$ & $0.935^{* * *}$ & 1 & -0.532 \\
\hline & sig & 0 & 0.041 & 0 & - & 0.114 \\
\hline \multirow{2}{*}{$\begin{array}{l}\text { Openness to the Outside } \\
\text { World }\end{array}$} & Relevance & 0.462 & 0.415 & $0.552^{*}$ & -0.532 & 1 \\
\hline & sig & 0.179 & 0.233 & 0.098 & 0.114 & - \\
\hline
\end{tabular}


*** means it's significant at $1 \%, * *$ means it's significant at $5 \%, *$ means it's significant at $10 \%$

Table 4 shows the Tobit regression results. It can be seen that the R2 of the regression model is 0.781 , which has a good fit, and the explanatory power of the model is over $78 \%$. According to the regression results of $\mathrm{Z}$ statistics and $\mathrm{P}$, the five variables have passed the significant test. Among them, economic development level, technological level and public awareness of environmental protection are remarkable at the level of $5 \%$, and government environmental protection management level and openness to the outside world are remarkable at the level of $1 \%$.

The level of economic development has a significant positive effect on the performance of environmental regulation in manufacturing industry. For every RMB10,000 yuan increase in regional per capita GDP, the level of environmental regulation performance in manufacturing industry increases by $8.8 \%$. This conclusion is consistent with the environmental preference theory of the Environmental Kuznets Curve. That is to say, with the development of economy and the improvement of per capita income in Chongqing, people's demand for high environmental quality is also rising synchronously. The strengthening of the people's environmental supervision will promote the government to improve the intensity of environmental regulation and the ability of environmental regulation, so it will also improve the performance of environmental regulation of manufacturing industry in Chongqing to a certain extent. The government's environmental management level has a significant positive effect on the environmental regulation performance of manufacturing industry. The proportion of government's environmental expenditure has increased by one unit, and the performance level of manufacturing industry's environmental regulation has increased by $7.9 \%$. This shows that the government's environmental management level has a great role in promoting the environmental regulation performance of manufacturing industry in Chongqing. The stronger the government's environmental management level, the easier the environmental regulation policy can be implemented, and the higher the efficiency of implementation. Public awareness of environmental protection has a significant positive effect on the performance of environmental regulation in manufacturing industry. For every unit of increase in public awareness of environmental protection, environmental regulation performance of manufacturing industry increased by $0.3 \%$. This indicates that increasing public attention to environmental protection will promote the government to strengthen the supervision of industrial enterprises and improve the performance level of environmental regulation.

The degree of openness to the outside world has a significant negative impact on the environmental regulation performance of manufacturing industry in Chongqing. For every unit of foreign investment increased, the environmental regulation performance decreased by about $0.45 \%$ [5]. The more foreign-invested enterprises, the larger the scale, and the stronger the ability to negotiate with the government, the worse the performance of environmental regulation is. Technological level and environmental regulation performance of manufacturing industry are also negatively correlated, which shows that technological improvement of Chongqing industrial enterprises is mainly to improve product performance and product quality or develop new products before large-scale production, rather than to improve pollution control technology or reduce the use of pollutant production. Therefore, in the process of technological transformation, they will increase the total amount of pollutant emissions because of technological changes.

Table 4 Tobit regression results of factors affecting environmental regulation performance of manufacturing industry in chongqing

\begin{tabular}{|c|c|c|c|c|}
\hline Variables & Coefficients & $\begin{array}{c}\text { Standard } \\
\text { Deviation }\end{array}$ & Z statistics & $\mathrm{P}$ value \\
\hline Constant term & 0.467 & 0.160 & 2.921 & $0.004^{* * *}$ \\
\hline Economic Development Level & 0.088 & 0.0433 & 2.032 & $0.042^{* *}$ \\
\hline $\begin{array}{c}\text { Government Environmental Protection } \\
\text { Management Level }\end{array}$ & 0.079 & 0.026 & 3.079 & $0.002^{* * *}$ \\
\hline Public Awareness of Environmental Protection & 0.003 & 0.00345 & 0.869 & $0.045^{* *}$ \\
\hline Technical Level & -0.0063 & 0.00028 & -2.245 & $0.025^{* *}$ \\
\hline Openness to the Outside World & -0.0045 & 0.00012 & -3.668 & $0.000^{* *}$ \\
\hline
\end{tabular}




\section{Conclusion}

\subsection{Economic development level}

Economic development level has a significant positive impact on the performance of environmental regulation of manufacturing industry in Chongqing. With the improvement of the level of economic development, the performance of environmental regulation will increase to a certain extent. The environmental preference theory of the Environmental Kuznets Curve has been proved in the performance of environmental regulation of manufacturing industry in Chongqing. The influence of economic development level on environmental quality can be explained from three aspects: scale effect, technology effect and structure effect.

From 2008 to 2017, Chongqing is in a period of rapid economic development. With the continuous improvement of industrial development level, the rapid growth of industrial scale, environmental pollution is aggravated. During that period, the improvement of Chongqing's economic development level has also promoted the improvement of enterprise's technological level to a certain extent, including the improvement of the utilization efficiency of environmental resources and the level of pollution control, reducing the generation of pollutants from the source and the discharge of pollutants from the end. At the same time, with the development of economy to a certain extent, the level of per capita income has been raised, and people have paid more attention to the quality of the environment. On the one hand, it will promote the adjustment of industrial structure and the upgrading and transformation of manufacturing industry. The heavily polluted industries will gradually withdraw, and the emerging industries with lighter pollution and higher output value will emerge. On the other hand, it will increase the pressure of government environmental regulation, forcing it to improve environmental regulation and reduce pollutant emissions, so as to improve environmental quality to meet the needs of the masses.

\subsection{Government environmental protection management level}

The level of government environmental protection management plays a significant role in promoting the environmental regulation performance of manufacturing industry in Chongqing, and there is an obvious positive correlation between the two, indicating that the improvement of environmental regulation performance of manufacturing industry in Chongqing largely depends on the improvement of government environmental protection management level. To some extent, the environmental management level of the government reflects the emphasis the government attaches to environmental protection. The stronger the government's environmental protection management level is, the greater the investment in environmental regulation will be, and more stringent environmental regulation policies will be adopted, such as comprehensive using to improve industry local emission standards, increasing penalties for over-standard emission enterprises, establishing environmental credit lists, improving enterprise environmental information disclosure, strengthening the strength of environmental regulation and improving the scientific nature of environmental regulation system. At the same time, with the increase of the proportion of environmental protection expenditure in fiscal expenditure, the government will pay more attention to the income brought by the increase of investment, especially focusing on whether the effect of environmental regulation obtained is equal to the increase of environmental regulation investment. Increased government investment in environmental regulation will not only raise the concern about the relationship between the improvement of government regulation performance, but also improve the environmental regulation performance of manufacturing industry in Chongqing. Therefore, the government's awareness of environmental protection will also improve the environmental regulation performance of manufacturing industry in Chongqing.

\subsection{Public awareness of environmental protection}

Public awareness of environmental protection can significantly promote the performance of 
environmental regulation in manufacturing industry, and the improvement of public awareness of environmental protection can positively affect the performance of environmental regulation. The government is the manager of social life, and has an inescapable responsibility for social development. One of the basic responsibilities of the government is to meet the basic needs of the public. In modern society, the public's awareness of environmental protection is increasing, and the requirement for the quality of living environment is also getting higher and higher. The public's pursuit of a good living environment will prompt them to choose environmental friendly products on their own initiative and generate sustained attention to environmental protection, which will correspondingly increase the pressure of environmental protection. Through complaints, the public strengthens the environmental awareness of the impact on the performance of environmental regulation in manufacturing industry, and realizes the transmission of environmental protection pressure to the government. The stronger the public awareness of environmental protection, the higher the demand for high-quality environment, the higher the attention to ecological environment work and environmental regulation. The greater the pressure transmitted to the government, the higher the input of government environmental regulation. Industrial enterprises are the focus of complaints, so the environmental regulation performance of manufacturing industry can be improved.

\subsection{Technical level}

The improvement of technological level of industrial enterprises has a significant negative impact on the environmental regulation performance of manufacturing industry. The higher the technological level of manufacturing industry, the lower the environmental regulation performance of government. This shows that the main purpose of technological transformation of Chongqing industrial enterprises at the present stage is to improve the performance of their products, improve product quality or carry out large-scale production after developing new products, resulting new pollutant emissions. Although the improvement of technology level has a certain effect on reducing the production and emission of pollutants, on the whole, the emission of pollutants from manufacturing industry may not be reduced. Therefore, the improvement of technological level of industrial enterprises in Chongqing has not achieved a considerable improvement in the performance level of environmental regulation of manufacturing industry.

However, according to the research results of many scholars, in general, there is a positive correlation between the technological level of enterprises and the performance of environmental regulation. This is because the higher the technological level, the stronger the innovation ability of enterprises and the better the pollution control technology. Under the incentive of the government's scientific and reasonable environmental regulation policy, it is easier to achieve the standard of energy saving and emission reduction, and achieve lower pollution emissions [6]. Therefore, Chongqing Municipal Government should focus on guiding enterprises to carry out technological transformation in energy saving, emission reduction and cleaner production so as to improve the level of pollutant control and reduce the generation and discharge of pollutants.

\subsection{Openness to the outside world}

The degree of opening-up has a significant negative impact on the environmental regulation performance of manufacturing industry in Chongqing. The higher the degree of agglomeration of foreign-funded enterprises and the larger the scale of investment, the more obvious the advantages of foreign-funded enterprises in the process of game with the government, and the worse the environmental regulation performance will be.

The empirical results show that the higher the degree of openness, the lower the performance of environmental regulation. This is because foreign-funded enterprises are generally large in scale and have great economic benefits. Driven by tax revenue or GDP achievements, some district and county governments turn a blind eye to some illegal and irregular acts of foreign-funded enterprises and even give them unprincipled refuge when attracting investment. Thus, there is a "conspiracy between government and enterprise". In the process of environmental regulation, when the benefits of economic growth exceed the cost of social stability, there will be collusion between the 
government and some large enterprises. In the course of the game between enterprises and the government, some foreign-funded manufacturing enterprises with large investment and large tax revenue are more likely to be inclined by the government's environmental regulation policies because of their influential voice. This makes the government relax the environmental supervision over these enterprises, and the situation that the enterprise's pollutant discharge does not meet the standards or other environmental policies are not in conformity with the environmental policy. The phenomenon is tolerated or sheltered, which leads to the low performance of environmental regulation. The solution to eliminate the phenomenon of "collusion between government and enterprise" doesn't lying in controlling the scale of foreign investment, but to strengthen the regulation and supervision, and to use diversified environmental regulation means to eradicate the phenomenon of collusion fundamentally.

\section{Acknowledgements}

This work was sponsored in part by National Social Science Foundation of China (19XMZ095); Science and Technology Project of Chongqing Municipal Education Commission (KJ1600321); Chongqing Social Science Planning Project (2015QNJJ05).

\section{References}

[1] Barbera A J, Mcconnell V D. (1990) The impact of environmental regulations on industry productivity: Direct and indirect effects, Journal of Environmental Economics \& Management, 18(1): 50-65.

[2] Rubashkina Y, Galeotti M, erdolini E. (2015) Environmental regulation and competitiveness: Empirical evidence on the Porter Hypothesis from European manufacturing sectors, Energy Policy, 83(35): 288-300.

[3] Berman E, Bui L T M. (2001) Environmental Regulation and Productivity: Evidence from Oil Refineries. Review of Economics \& Statistics, 83(3): 498-510.

[4] Liu Shuai. (2019) Comments on Research on Industrial Regulation Reform in China, Statistics and Decision-making, 11(5): 2-3.

[5] Li Qiang, Wei Wei. (2019) Time Series Change and Influencing Factors of Environmental Regulation Efficiency in Yangtze River Economic Zone, Journal of North China Electric Power University, 3: 9-17.

[6] Li Shuying, Yu Ya-guai. (2018) Dynamic Evolution of Environmental Regulation Efficiency and Analysis of Its Influencing Factors in China- Based on the Super Efficiency DEA-Tobit. Science and Technology and Management, 20(3): 79-85. 